\title{
A Feasibility Study on GFRP Tubular Concrete Column Damage Detection Using Piezoceramic-transducer-enabled Active Sensing
}

\author{
Cai Gaojie, She Yanhua* \\ School of Urban Construction, Yangtze University, Jingzhou, China
}

Email address:

syh916@126.com (She Yanhua)

${ }^{*}$ Corresponding author

\section{To cite this article:}

Cai Gaojie, She Yanhua. A Feasibility Study on GFRP Tubular Concrete Column Damage Detection Using Piezoceramic-transducer-enabled Active Sensing. American Journal of Mechanics and Applications. Vol. 7, No. 3, 2019, pp. 64-70. doi: 10.11648/j.ajma.20190703.15

Received: November 3, 2019; Accepted: November 21, 2019; Published: December 3, 2019

\begin{abstract}
Aiming at the crack damage of concrete in GFRP tubular concrete column, a method based on piezoelectric wave method was developed to monitor the crack damage. By transmitting and receiving stress waves from a pair of piezoelectric ceramic sensors embedded in GFRP tubular concrete, the damage degree of GFRP tubular concrete columns was evaluated by using wavelet packets to obtain the stress wave energy and damage index under different load levels. By analyzing the change of stress wave energy and damage index of concrete with different strength under different loads, the time-domain signal response, load-energy curve and load-damage index curve were obtained. In this test, four test pieces were designed according to different concrete strength grades. Two piezoelectric ceramic sensors were placed in the test piece and used to monitor the test piece under static loading. After the static loading was completed, the GFRP tube was severely broken and peeled off from the concrete. A large number of cracks appeared on the concrete surface. The results show that: The test results were consistent with the actual damage of the specimen. The development trend of concrete damage in GFRP tubular concrete columns was well revealed by the wave method.
\end{abstract}

Keywords: Concrete Damage Detection, Active Sensing Approach, Piezoelectric Transducer, Wavelet-packet-based Damage Index

\section{Introduction}

GFRP tubular concrete column was a combined structure formed by pouring concrete into the GFRP tube. Compared with other confined concrete members, it had the advantages of strong bearing capacity, good integrity, high ductility, excellent corrosion resistance and easy construction. However, due to factors such as the environment and age, cracks in concrete could seriously affect the safety of the structure. Therefore, health monitoring of concrete columns was crucial.

With the latest developments in structural health monitoring [1-4] and damage detection technology [5-6], piezoelectric ceramic materials had become an ideal structural health monitoring material due to their high sensitivity, fast response, embeddability, strong piezoelectric effect, and dual functions of sensing and driving [7-13]. Song [14] told about the precautions of the sensor and how to use it. Xiao et al. [15] considered the influence of temperature on piezoelectric ceramic sensors. Huang et al. [16] mentioned how piezoelectric ceramic sensors were placed in concrete so that energy could be better accepted. Yan [17] buried piezoelectric ceramic sensor in concrete structure for damage monitoring.

However, few scholars had studied the damage identification of GFRP tubular concrete column. Therefore, this paper systematically studied the damage identification of GFRP tubular concrete column by wave method. The wavelet packet analysis method was used to calculate the energy of the stress wave signal when the concrete column was damaged, and then the damage index was obtained to reveal the damage of concrete in the GFRP tube. 


\section{Principles}

\subsection{Principle of Wave Method}

The basic principle of the wave method was that the piezoelectric sensor was attached to the surface of the structure or embedded in the structure, so that the piezoelectric sensor and the monitored structure form a piezoelectric intelligent structure system, which used one piezoelectric sensor to emit stress waves and the other to receive stress waves. By analyzing the difference between the received signals before and after the structural damage, the damage and defect of the structure could be identified, such as the damage and defect would cause the attenuation of signal amplitude, the change of mode and the delay of propagation time. Figure 1 showed the basic structure of health monitoring system by wave method.

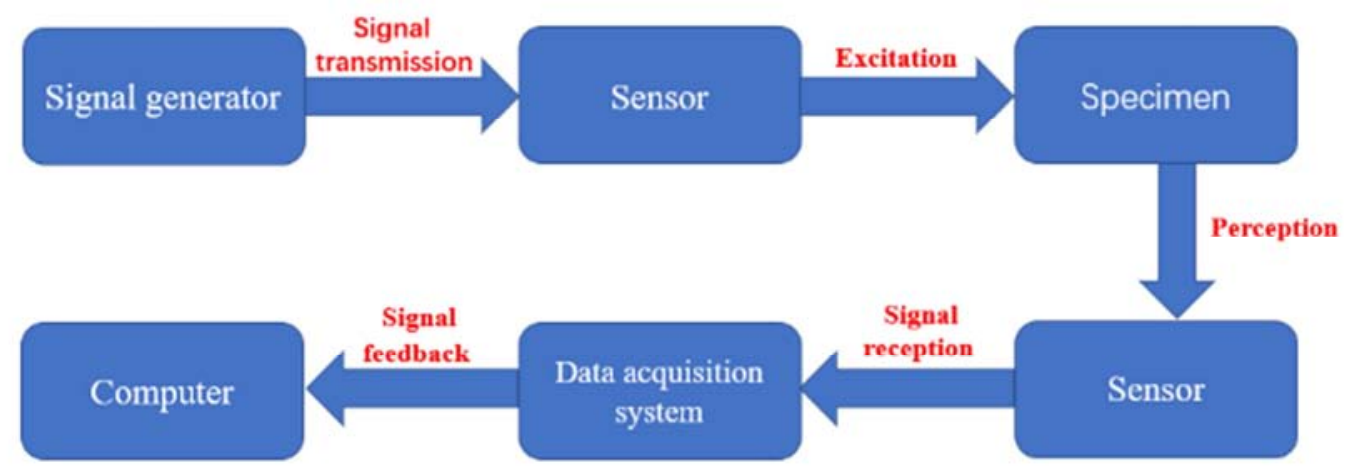

Figure 1. Block diagram of wave health monitoring system.

\subsection{Wavelet-Packet-Based Damage Index}

Wavelet packet theory analysis method is developed on the basis of wavelet theory analysis. This method fills in the feature that the high frequency signal cannot be decomposed in depth in wavelet theoretical analysis, and the higher the number of layers decomposed, the higher the resolution. Wavelet packet theory analysis is widely applied in the field of time - frequency signal recognition, signal noise elimination and feature extraction.

First, the received signal $S_{i}$ of the ith measurement is decomposed into $2^{5}$ subsets of signals with different frequency bands. The signal subset $\mathrm{X}_{\mathrm{i}, \mathrm{j}}$, where $\mathrm{j}$ is the frequency band $(\mathrm{j}=$ $\left.1,2, \ldots, 2^{5}\right)$, can be expressed as

$$
X_{i, j}=\left\{X_{i, j, 2}, \ldots, X_{i, j, m}\right\}
$$

where $\mathrm{m}$ is the number of data samplings of the decomposed signal subset

Second, energy can be defined as

$$
E_{i, j}=X_{i, j, 1}^{2}+X_{i, j, 2}^{2}+\ldots X_{i, j, m}^{2}
$$

Finally, the damage index can be defined as [18]

$$
S_{i}=\sqrt{\frac{\sum_{j=1}^{2^{5}}\left(E_{i, j}-E_{1, j}\right)^{2}}{\sum_{j=1}^{2^{n}} E_{1, j}^{2}}}
$$

The larger value of the damage index $\mathrm{Si}$, the higher damage degree of the test piece. When $S_{i}=0$, it indicates that the test piece is not damaged. When $S_{i}=1$, it indicates that the test piece is completely destroyed.

\section{Experimental Setup}

\subsection{Specimen Design}

In this test, four GFRP tubular concrete column specimens were designed according to different parameters, and the varying parameters were concrete strength grade. The concrete grade included $\mathrm{C} 10, \mathrm{C} 20, \mathrm{C} 30$ and $\mathrm{C} 40$. The specimen number and specific parameters were shown in table 1. The test GFRP tube was made of glass fiber and polyester resin. The wall thickness $(\mathrm{T})$ was $6 \mathrm{~mm}$, the column height $(\mathrm{H})$ was $250 \mathrm{~mm}$, the cross section was a square with side length (L) of $100 \mathrm{~mm}$, and the two sensors are $150 \mathrm{~mm}$ apart, as shown in figure 2.A pair of piezoelectric ceramic sensors were embedded in the concrete of the GFRP tube. One sensor SS1 was used as the driver to generate the stress wave signal, and the other sensor SS2 was used as the receiver to receive the stress wave signal.

Table 1. Specimen number and specific parameters.

\begin{tabular}{lllll}
\hline Specimen number & Height $\mathbf{H}(\mathbf{m m})$ & Length $\mathbf{L}(\mathbf{m m})$ & Wall thickness $\mathbf{T}(\mathbf{m m})$ & $\begin{array}{l}\text { Concrete grade } \\
\mathbf{C}(\mathbf{M P a})\end{array}$ \\
\hline GC10 & & 60 & 6 & $\mathrm{C} 10$ \\
GC20 & 100 & 6 & $\mathrm{C} 20$ \\
GC30 & 100 & 6 & $\mathrm{C} 30$ \\
GC40 & 100 & 6 & $\mathrm{C} 40$ \\
\hline
\end{tabular}



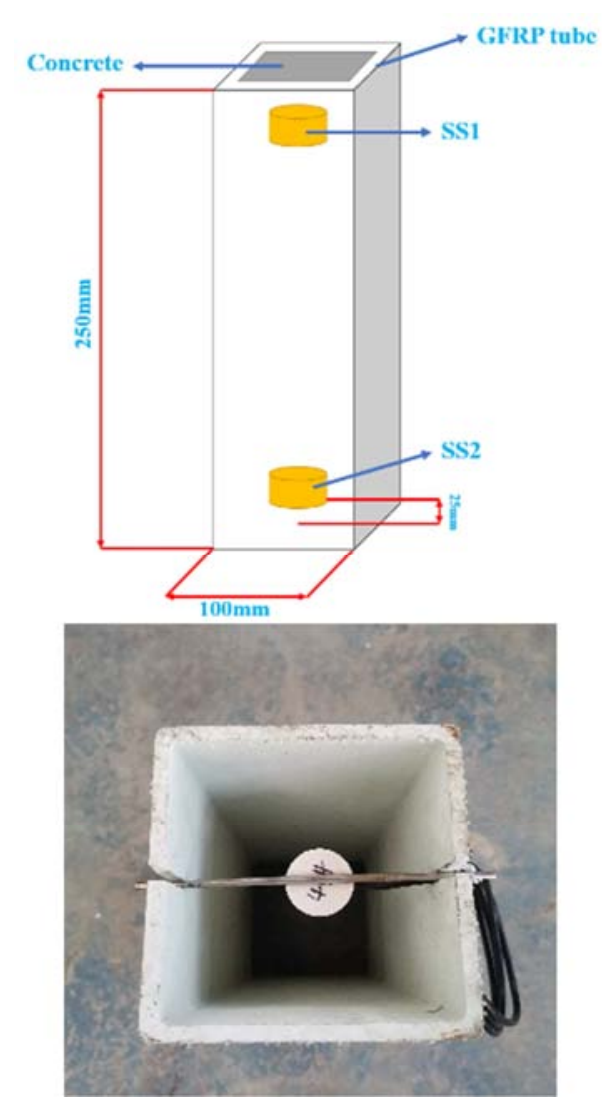

Figure 2. Schematic diagram of GFRP concrete short column and photos of specimen.

\subsection{Material Performance}

The standard test piece was taken on the surface of the GFRP tube for testing. The average compressive strength was $118 \mathrm{MPa}$, the tensile strength was $550 \mathrm{MPa}$, and the specific gravity was $2000 \mathrm{~kg} / \mathrm{m}^{3}$. The test concrete was made into a standard cube fast, numbered $\mathrm{C} 10, \mathrm{C} 20, \mathrm{C} 30, \mathrm{C} 40$. The average compressive strength of $\mathrm{C} 10, \mathrm{C} 20, \mathrm{C} 30$ and $\mathrm{C} 40$ measured on the test machine were $15.7 \mathrm{MPa}, 23.9 \mathrm{MPa}, 31.7$ $\mathrm{MPa}$ and $41.3 \mathrm{MPa}$, respectively. All test pieces tested were shown in Figure 3.
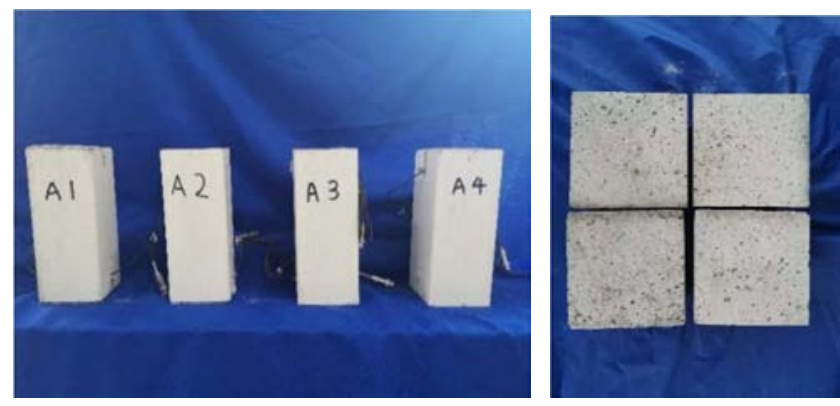

Figure 3. GFRP tube concrete column and standard cube block.

\subsection{Loading and Testing}

The cross section of the test piece was smoothed before each test to prevent bias during loading. As shown in Figure 4, the load was implemented by a $1000 \mathrm{kN}$ electro-hydraulic servo universal testing machine, and the displacement control loading mode was adopted at a rate of $0.5 \mathrm{~mm} / \mathrm{min}$. As shown in Figure 5, the entire health monitoring system consists of a signal generator, a signal acquisition and analysis system, and a computer. The signal generator acted as a signal source that excited SS1 to generate stress waves. The signal acquisition and analysis system used the USB-6361 signal collector to collect the stress waves received by SS2 and finally stored the data in the computer. The frequency sweep mode was adopted in the experiment. The amplitude of the frequency sweep signal was $10 \mathrm{~V}$, the frequency range was $100 \mathrm{~Hz}-5000 \mathrm{kHz}$, and the period was $1 \mathrm{~s}$. During the static loading process, the load was recorded every 30 seconds, and a stress wave was collected once, and the load was stopped immediately when the ultimate bearing capacity was reached.

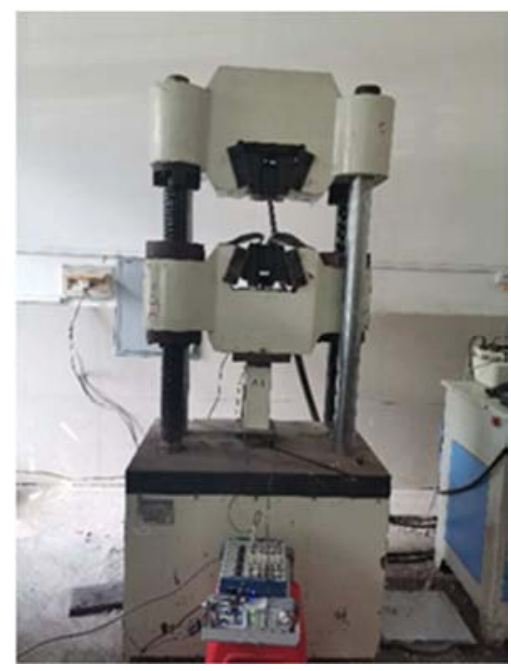

Figure 4. Loading device.

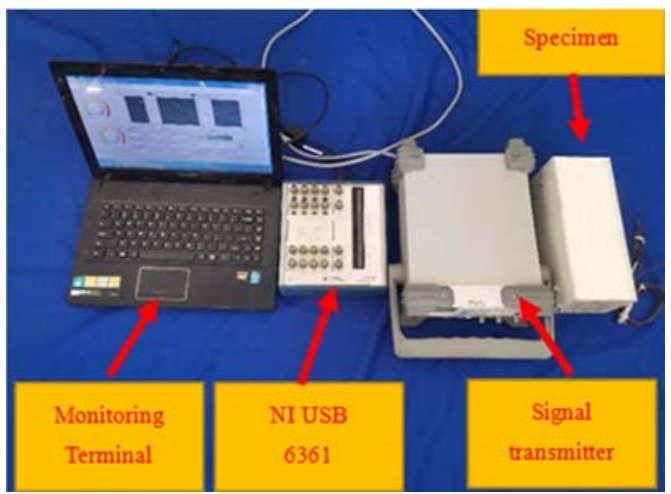

Figure 5. Monitoring System.

\section{Results and Discussion}

\subsection{Destruction Mode}

After the static loading was completed, the sidewall of the GFRP tube was greatly damaged. The concrete was peeled off from the GFRP tube and the internal concrete failure mode was observed, as shown in Figure 6. The GC40 concrete 
column had the smallest crack width and the least number of cracks. The GC10 concrete column had the largest crack width and the largest number of cracks. The results showed that the

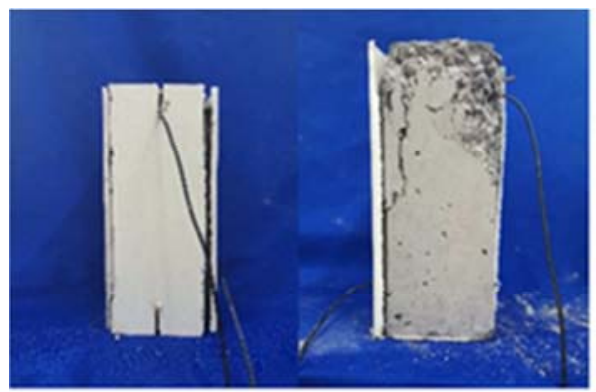

(a) GC10

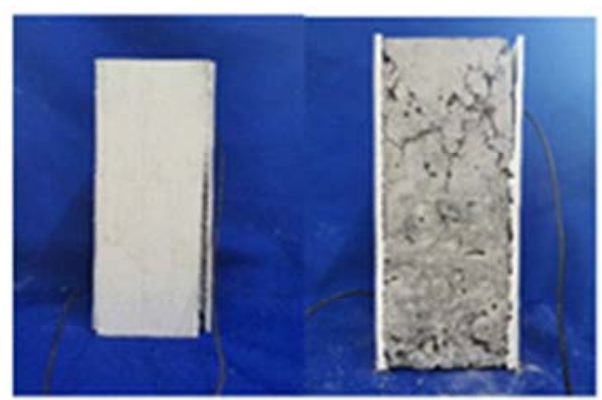

(c) 0 C 30 higher the concrete strength, the stronger the ability to resist damage.

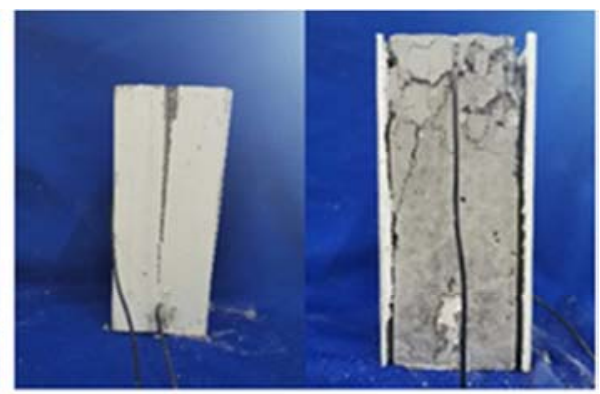

(b) $\operatorname{GC} 20$

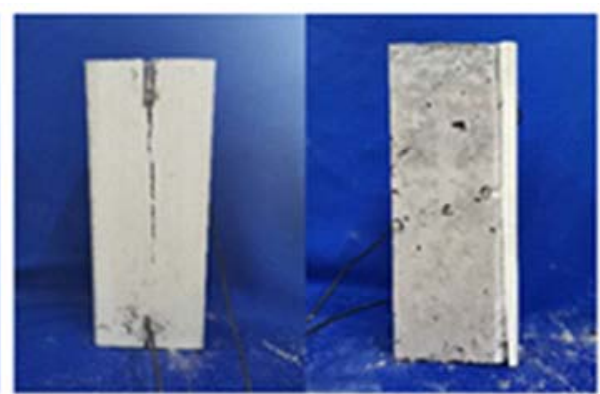

(d) $\mathrm{CC} 40$

Figure 6. Before and after GFRP tube peeling.

\subsection{The time-domain Signal Response}

The sensor PZT time-domain signal response of the test pieces GC10, GC20, GC30 and GC40 were shown in Figure 7. Each curve was a periodic signal of the response of the swept sine wave sensor signal, and the period was $1 \mathrm{~s}$. During the static loading process of the test piece, in the initial stage of the load, the concrete in the GFRP tube was compressed, and the pores inside the concrete become smaller, which was beneficial to the signal transmission. At this time, the voltage values of the sensor receiving the signal became large, and gradually reached the maximum values. After that, as the load further increased, the concrete was damaged by the pressure, and the micro cracks began to develop, which was not conducive to the signal transmission. The voltage values of the sensor receiving the signal began to gradually decrease. The results showed that the damage degree of the test piece was different, and the signal received by the sensor would be different. The more severe the damage of the test piece, the smaller the sensor voltage values of the received signal.

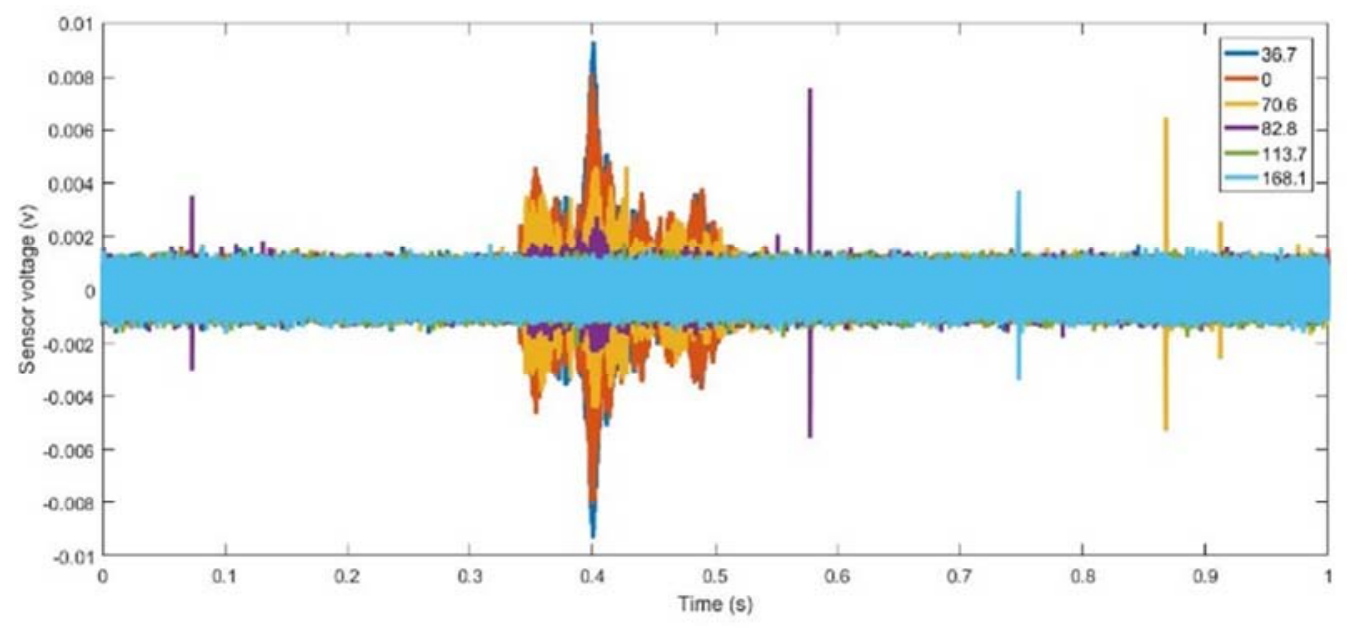

(a) GC10 


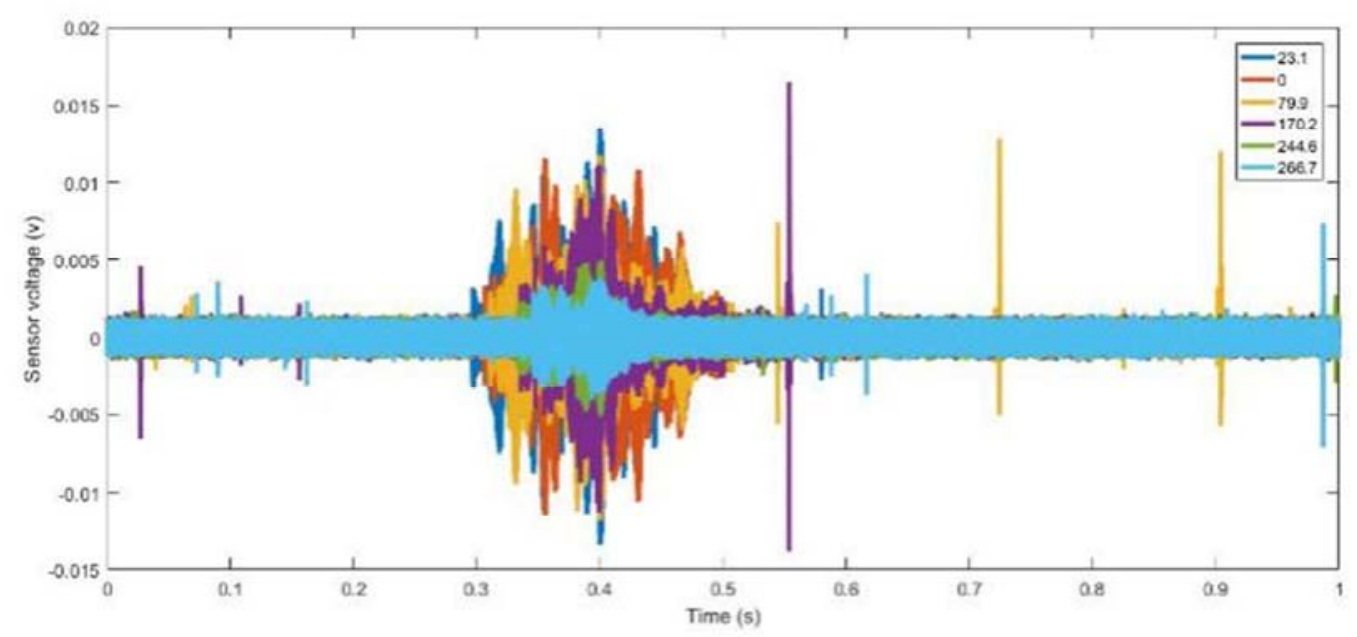

(b) $\mathrm{GC} 20$

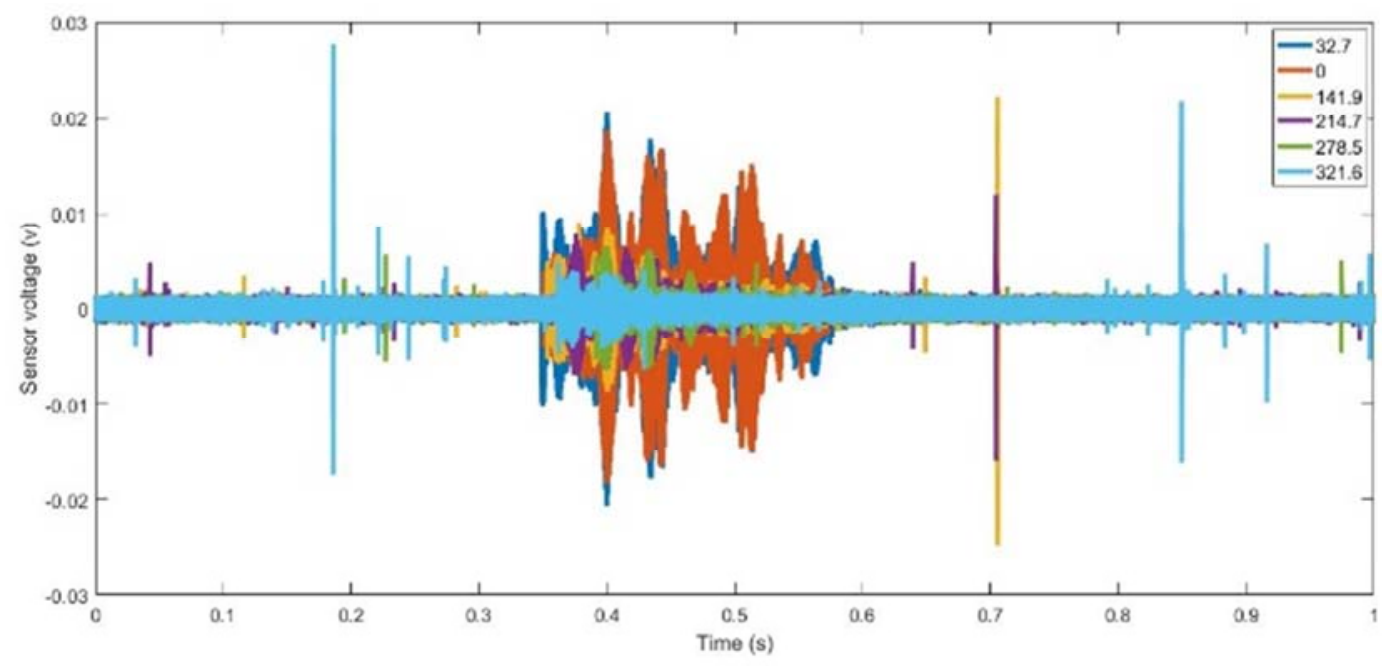

(c) GC30

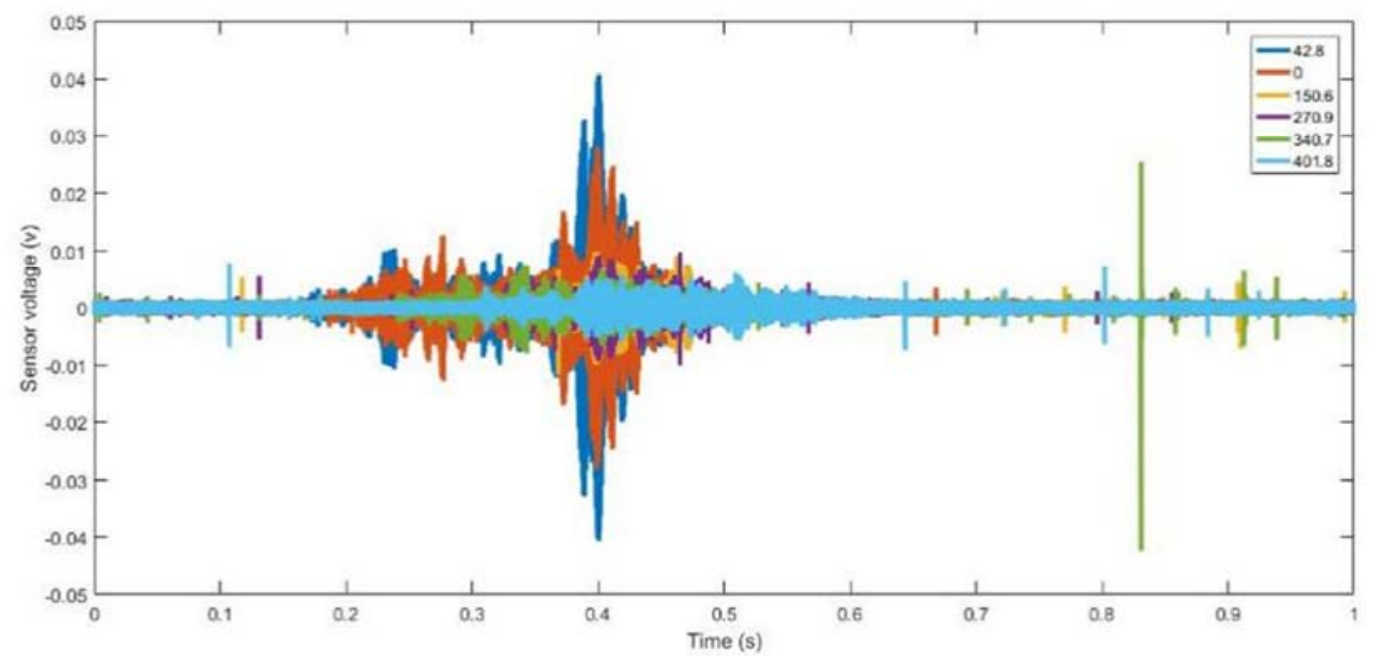

(d) GC40

Figure 7. The time-domain signal response.

\subsection{Load-energy Curve}

In order to quantitatively evaluate the loss of stress wave energy, the collected data was analyzed and calculated by wavelet packet, and the load-energy curve of the test piece was 
obtained. As shown in Figure 8, compared with the time domain signal diagram, the load-energy curve was more concise and intuitive, and could more express the trend of the degree of concrete damage. The greater the energy values, the smaller the damage. As the load increases, the overall trend of the energy values of the test pieces GC10, GC20, GC30 and GC40 was constantly decreasing, and the damage of the test piece was also increasing. When the test piece was broken, the energy values of the test piece GC40 was the largest, and the energy values of the test piece GC10 was the smallest. It was indicated that the final damage was sequentially reduced from the test piece GC10 to the test piece GC40. The results of the monitoring were consistent with the actual condition of the specimen damage as shown in Figure 6, In addition to this, the initial energy values of the test pieces GC10, GC20, GC30 and GC40 were sequentially increased. It showed that the higher the concrete strength level, the larger the initial energy values. The strength of the concrete could be determined by the initial energy values.

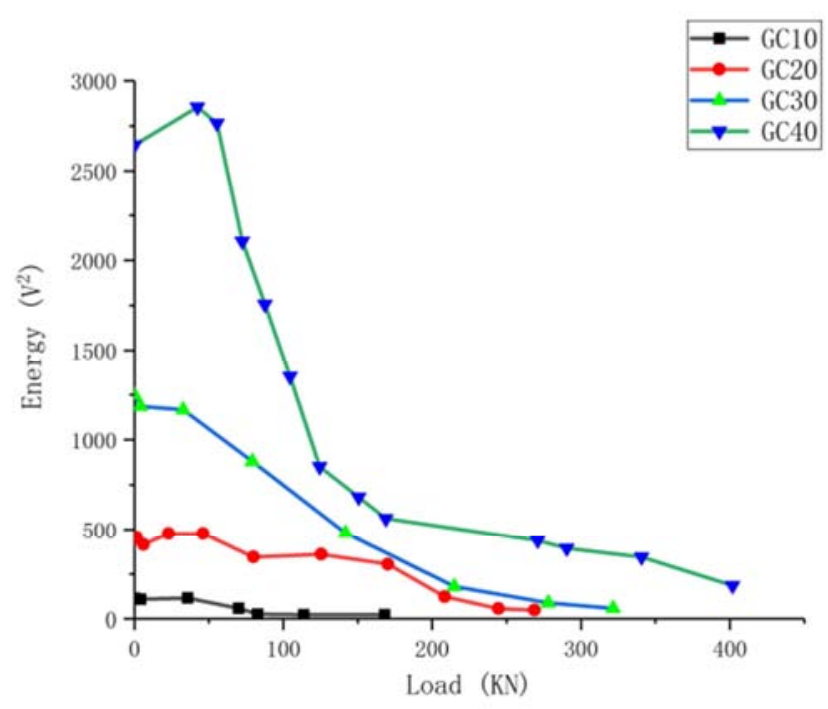

Figure 8. Load-energy curve.

\subsection{Load-damage Index Curve}

Although the load-energy curve could reflect the trend of concrete damage, it could not be quantified specifically. Therefore, based on the load-energy curve, the damage index was calculated and the load-damage index curve was drawn. As shown in Figure 9, with the increase of load, the overall trend of damage index of all specimens was increasing, and they all gradually approached 1 from 0 . A damage index of 0 indicated that the concrete was not damaged, and a damage index of 1 indicated complete destruction of the concrete. This was consistent with the gradual destruction of the test piece as the load increases. Moreover, the final damage index of the test piece was from GC10, GC20, GC30, and GC40. It was indicated that the damage degree of the specimen is $\mathrm{GC} 10$, GC20, GC30, GC40. This was the same as the actual situation as shown in Figure 6.

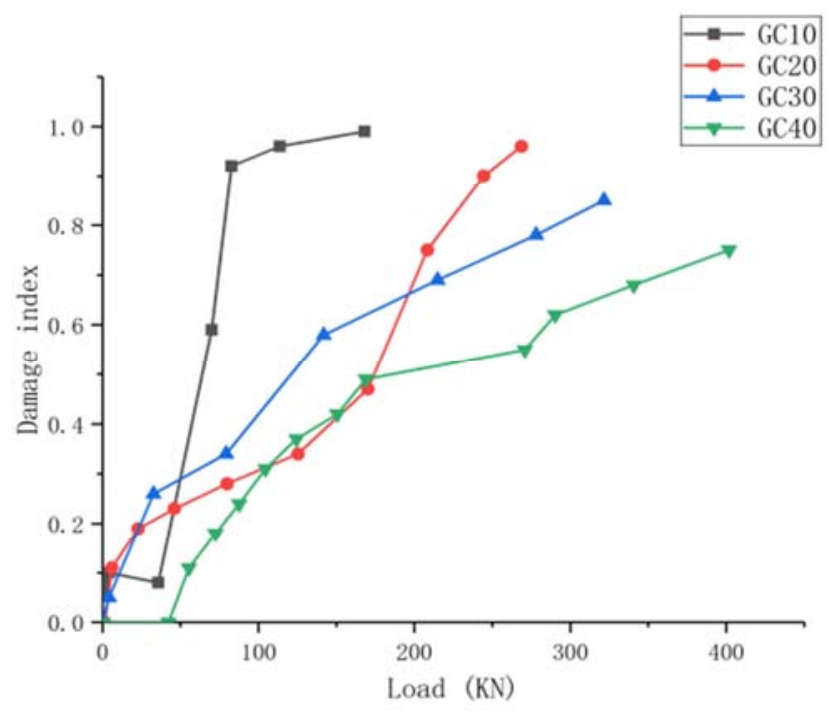

Figure 9. Load-damage index curve.

\section{Conclusion}

In this paper, the piezoelectric wave method and the wavelet packet damage index are used to monitor the concrete damage in GFRP tubular concrete column. As the concrete damage increased, the signal amplitude showed a significant downward trend. The change in energy values was simple and intuitively expresses the trend of the degree of concrete damage. The experimental results showed that the method could be used as an effective tool for real-time monitoring of GFRP tube concrete column damage.

\section{Acknowledgements}

This work is financially supported by National Natural Science Foundation of China ( NSFC, 51408057) \& Youth Talent Project of Yangtze University (2015cqr06).

\section{References}

[1] G. Song, C. Wang, B. Wang, "Structural Health Monitoring (SHM) of Civil Structures." Appl. Sci. 2017, 7, pp. 789.

[2] Y. Yang, B. S. Divsholi, C. K. Soh, "A reusable PZT transducer for monitoring initial hydration and structural health of concrete." Sensors 2010, 10, pp. 5193-5208.

[3] S. Yan, H. Ma, P. Li, G. Song, J. Wu, "Development and Application of a Structural Health Monitoring System Based on Wireless Smart Aggregates." Sensors 2017, 17, pp. 1641.

[4] W. H. Duan, Q. Wang, S. T. Quek, "Applications of piezoelectric materials in structural health monitoring and repair: Selected research examples." Materials 2010, 3, pp. 5169-5194.

[5] D. Broda, W. J. Staszewski, A. Martowicz, T. Uhl, V. V.Silberschmidt, "Modelling of nonlinear crack-wave interactions for damage detection based on ultrasound-A review." J. Sound Vib. 2014, 333, pp. 1097-1118. 
[6] X. Hu, H. Zhu, D. Wang, "A study of concrete slab damage detection based on the electromechanical impedance method." Sensors 2014, 14, pp. 19897-19909.

[7] C. Yu and L. Ping, "Piezoelectric-ceramic-embedded smart concrete module for structure health monitory." SENSORS, 2009 IEEE, 2009.

[8] J. Shao, T. Wang, H. Yin, D. Yang, Y. Li, "Bolt looseness detection based on piezoelectric impedance frequency shift. " Appl. Sci. 2016, 6, pp. 298.

[9] D. Zou, T. Liu, C. Liang, Y. Huang, F. Zhang, C. Du, "An experimental investigation on the health monitoring of concrete structures using piezoelectric transducers at various environmental temperatures." J. Intell. Mater. Syst. Struct. 2015, 26, pp. 1028-1034.

[10] D. Zou, T. Liu, G. Qiao, Y. Huang, B. Li, "An experimental study on the performance of piezoceramic-based smart aggregate in water environment." IEEE Sens. J. 2014, 14, pp. 943-944.

[11] D. Wang, H. Song, H. Zhu, "Embedded 3D electromechanical impedance model for strength monitoring of concrete using a PZT transducer." Smart Mater. Struct. 2014, 23, pp. 115019.

[12] D. Wang, J. Zhang, H. Zhu, "Embedded electromechanical impedance and strain sensors for health monitoring of a concrete bridge." Shock Vib. 2015, 2015, pp. 821395.
[13] G. Song, X. Zhou, W. Binienda, "Thermal deformation compensation of a composite beam using piezoelectric actuators. Smart Mater." Struct. 2003, 13, pp. 30.

[14] G. Song, C. Olmi and H. Gu, "An overheight vehicle-bridge collision monitoring system using piezoelectric transducers." Smart Materials and Structures 16.2 (2007), pp. 462-468.

[15] S. X. Xiao, et al, "Multiscale Analysis of Concrete Damage and Crack Propagation Under High Cycle Loading." International Journal of Computational Methods (2018), pp. 1844007.

[16] R. Huang, et al, "The Acoustic Directivity and Energy Research of Piezoelectric Ceramic Wafer Embedded in Concrete." Chinese Journal of Sensors and Actuators 24.9 (2011), pp. 1270-1274.

[17] Z. X. Yan, et al, "Concrete structure monitoring based on built-in piezoelectric ceramic transducers." Proceedings of SPIE - The International Society for Optical Engineering 6932 (2008), pp. 693208-693208-8.

[18] J. C. Zhang, Y. S. Huang, Y. Zheng, "A Feasibility Study on Timber Damage Detection Using Piezoceramic-Transducer-Enabled Active Sensing." Sensors 2018, 18, pp. 1563. 